\title{
New discoveries with geophysics in the Accademia of Hadrian's Villa near Tivoli (Rome)
}

\author{
M. De Franceschini* and A. M. Marras ${ }^{1}$ \\ ${ }^{1}$ University of Trento, Department of Achaeology, History and Cultural Heritage, Trento, Italy \\ *in cooperation with the University of Trento, Trento, Italy
}

Received: 26 August 2009 - Revised: 18 December 2009 - Accepted: 2 February 2010 - Published: 9 March 2010

\begin{abstract}
The Accademia Pilot Project concerns one of the lesser known buildings of Hadrian's Villa, the Accademia, which is still in private property and is not open to the public. One of the most significant and unique features of this building - and of the whole Villa - is a network of subterranean service corridors, which was seldom studied.

For the first time we used Geophysics at Hadrian's Villa, to explore the subterranean tunnels of the Accademia and reconstruct their layout. The survey was done by archaeologist Anna Maria Marras for her Master thesis in Geo-technology (Marras, 2008) and gave very interesting results.
\end{abstract}

\section{Introduction}

The Accademia Pilot Project is focused on the Accademia and the surrounding grounds of the Accademia Esplanade (plan Fig. 1), which is the highest artificial terrace of the Villa - a real Acropolis - and belongs to the Bulgarini family since the XVII century.

Information on the Accademia strongly needs to be updated: the last excavations were made in the XIX century, the most recent (and incomplete) plan was published in 1950, while other surveys remained unpublished.

The project consists of five main phases:

1. Collection of archive documents and previous bibliography: maps, plans, engravings and pictures, antiquarian and modern texts.

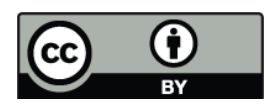

Correspondence to: M. De Franceschini (mdfmdf28@libero.it)
2. General survey of visible and standing structures: with Total Station, Gps, Laser Scanner, Photogrammetry, to draw a brand new plan of the building and the surrounding area.

3. Search of buried structures and subterranean tunnels known from antiquarian plans.

4. Remote sensing: Lidar and Infra-red photographs.

5. Data processing, creation of a GIS data base, publication and dissemination of results.

\section{Comparing ancient and modern plans}

The Accademia had a main entrance or Belvedere ( $\mathrm{A}$ in plan of Fig. 2), a central porch (B), a large apsed court named Zooteca (C) and a great circular hall, the so called Apollo's Temple (D), its best preserved structure. On the northern side of the porch was a stair $(\mathrm{F})$, descending to the subterranean service tunnels.

The most significant antiquarian plans of the Accademia are two: the older one is by Francesco Contini (the first general plan of the Villa), published in 1668. The second was drawn a century later by Giovan Battista Piranesi, and published after his death by his son Francesco, in 1781. This plan was largely copied by the subsequent scholars, including modern ones like Eugenia Salza Prina Ricotti.

Two german scholars made the most recent surveys of the site: Heinz Kähler, who published a partial plan in 1950, and Friedrich Rakob, who worked in the Accademia in the years 1991-1993 with architects Faller, Helfgen and Krück; their work is still unpublished, but I was able to see the documents

Published by Copernicus Publications on behalf of the European Geosciences Union. 


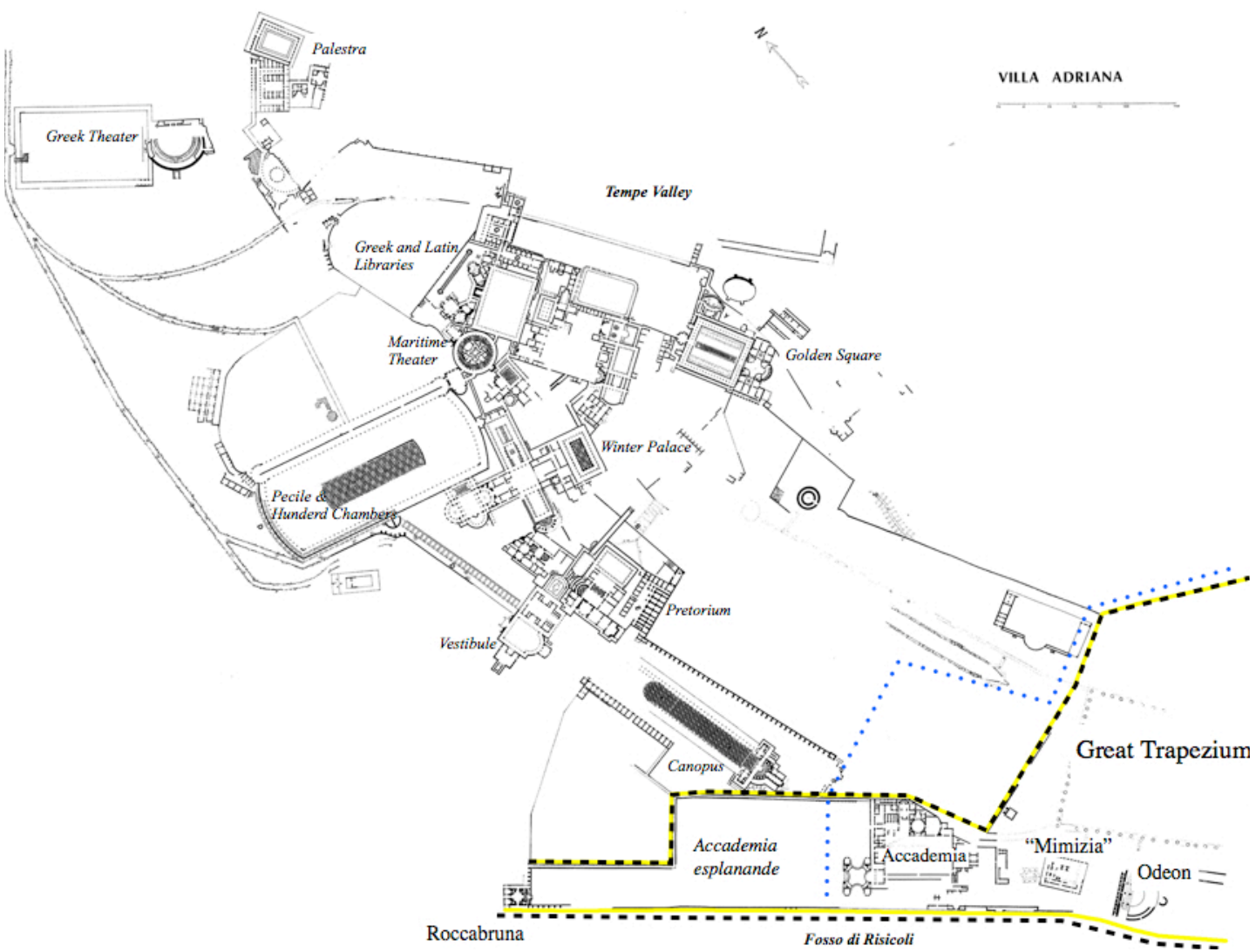

Fig. 1. General plan of Hadrian's Villa: on lower right is outlined the Accademia Esplanade area. Blue dots mark the border between public and private property (from Salza Prina Ricotti, 1982).

and the drawings. Also the american architects Robert Mangurian and Mary-Ann Ray worked for several years in the Villa, ad surveyed the Accademia from 1990 to 1995; they too gave me some pictures and plans, precious documentation of their work, which is still unpublished.

During the third phase of our project we decided to focus on the subterranean service corridors. The plan by Piranesi (Fig. 3, n. 1) shows a Cryptoporticus (A) and several corridors linked to it (B). Eugenia Salza Prina Ricotti published two plans of the Accademia (Fig. 3, nos. 2-3) with two different proposed layouts for the same corridors (B). The new plan produced by our survey (Fig. 3, n. 4) showed that the plan of Piranesi and the first plan of Salza Prina Ricotti (1982) are quite accurate, while her later plan (2000) was proven wrong as far as corridor B is concerned.

In the previous plans are drawn other tunnels linked to the stair F, on the northern side of the porch (Fig. 4). The preparatory drawing (now in Naples in the Library of the Certosa di San Martino) and the final plan published by Piranesi show a stair (F) and a $\mathrm{T}$ shaped a subterranean corridor (C), which was parallel to the northern side of the porch (Fig. 4ab). They also show the Cryptoporticus (A), and the related tunnels under the apsed room (B).
The two plans by Salza Prina Ricotti (1982 and 2000, Fig. 4c-d) show a completely different layout: tunnel $\mathrm{C}$ is $\mathrm{V}$ shaped, and in the plan of 2000 is hypothetically connected with a "new" bearing of tunnel B, passing under the circular hall of the so called Apollo's Temple. The plan of Cryptoporticus $\mathrm{A}$ is more or less the same in all plans.

Since the layout of the tunnels $\mathrm{C}$ was different in each plan, we needed to understand which one was correct; we also intended to reconstruct the whole network of the subterranean tunnels.

\section{New non-destructive technologies: geophysics}

Unfortunately, it is not possible to make excavations in the Accademia, because of the bureaucracy involved and - last but not least - the usual lack of funding. Therefore we decided to make the most of the new technologies available today, such as Geophysics. First of all, we had to decide which instrument could give the best result: Magnetometer, Ground Penetrating Radar (GPR) or Geo-resistivimeter?

Magnetometer was the first option out: the grounds of the Accademia are full of iron scraps and barbed-wire, so we knew that it was not going to work. We were doubtful also 


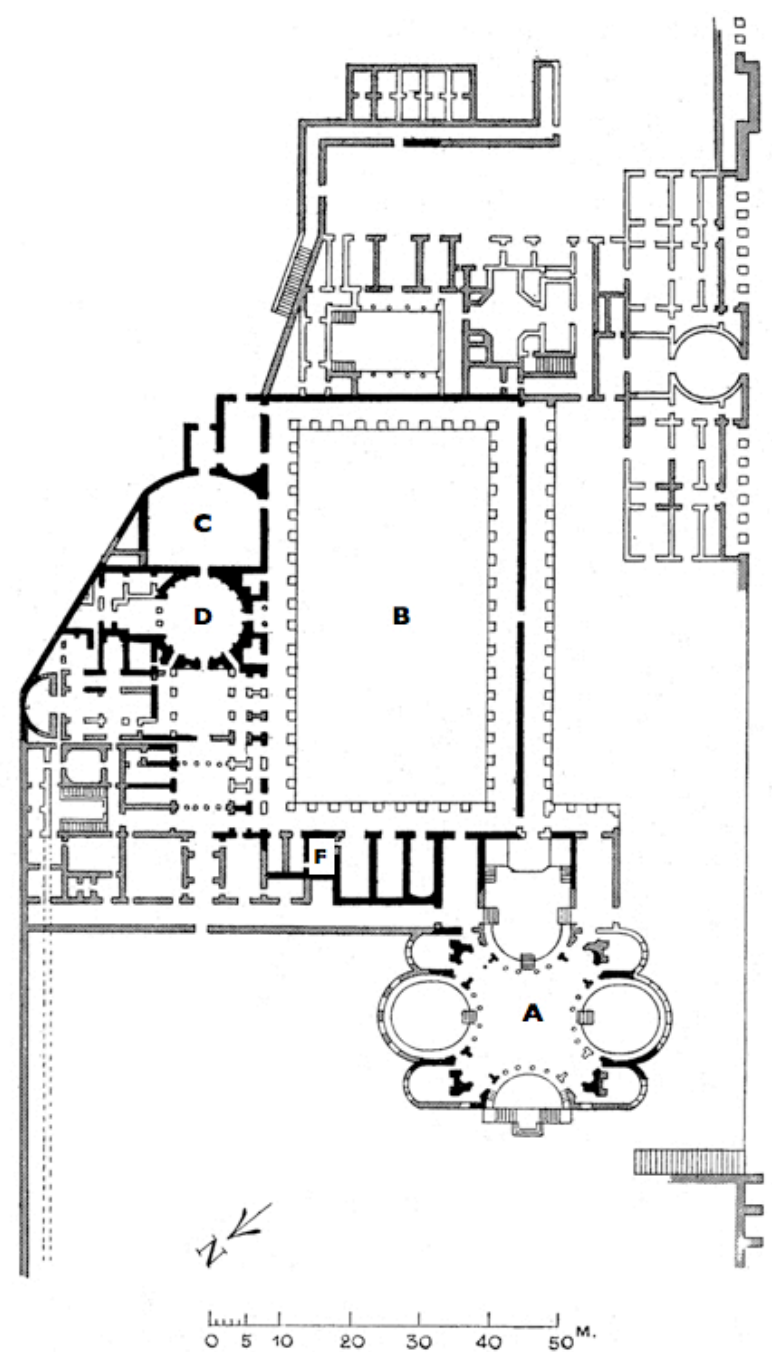

Fig. 2. Plan of the Accademia: (A) Belvedere; (B) inner porch; (C): so called Zooteca; (D): Apollo's Temple; (F): stair descending to the subterranean tunnels (from Winnefeld, 1895).

about Ground Penetrating Radar (GPR), since we did not know how the tunnels excavated in the tufa rock and filled with tufa sherds and dirt would respond to the instrument.

Finally we decided to use a Geo-resistivimeter: the experimental survey - as we said - was the subject of the Geotechnology Master thesis of archaeologist Anna Maria Marras, at the University of Siena. We had very interesting results and we plan to extend the search to the rest of the Accademia building and surrounding area.

\section{The survey}

We decided to start our survey measuring the subterranean tunnel linked to stair F (Fig. 5), on the northern side of the Accademia main porch. This stair goes down for a couple of meters, giving access to a V shaped tunnel C (Fig. 6) which is still partly visible and accessible in the initial part, while the rest is filled with dirt and debris. This was the ideal situation to test the instrument and to adjust it in order to detect the following buried sections of the tunnels. The results were extremely interesting.

Starting from the geological features of the ground, we were able to map the resistivity according to the values that are peculiar of tufa rock. They were compared to the resistivity values of limestone, travertine and marble, and also with the signals coming from the empty space of hollows that we were expecting to find while searching for the subterranean tunnels.

Our scale has 17 different colors, each one corresponding to a single resistivity value (Fig. 7). The undisturbed geological strata at the lower level correspond to the tufa rock, whose resistivity value is below $160 \mathrm{ohm}$. Within this range of values, the lower ones (Fig. 7, on the left side of our scale blue colors) are due to a higher moisture within the tufa rock itself.

Higher resistivity values (Fig. 7, on the right side of our scale - orange colors) are due to the presence of building materials such as marble, travertine and limestone, which have a higher resistivity rate than tufa rock. Generally speaking, in the strata closer to the surface these materials are mixed with tufa sherds, giving another response on the instrument.

Since our research was focused on subterranean tunnels, it is important to point out that when a cavity or hollow is wide enough to be detected by the Geo-resistivimeter, its resistivity values are extremely high (Fig. 7, far right of our scale deep red colors). This data must be cross-checked with the position and depth of the hollow space.

We used a Terrameter SAS 1000 Geo-resistivimeter (Fig. 8), built by Abem Instrument (Sweden), working with metallic electrodes (Fig. 9) with galvanic coupling. We created a grid, made of 17 different measurements, set 4$5 \mathrm{~m}$ apart one from the other (Figs. 10-11). The length of each measurement ranged from 31.5 to $37.81 \mathrm{~m}$, and the distance between cathodes was $0.50-0.60 \mathrm{~m}$. We chose to use a Schlumberger Array (Fig. 12), reaching a maximum depth of $10 \mathrm{~m}$.

We explored tunnel $\mathrm{C}$, which is still accessible for about $6 \mathrm{~m}$, reaching the point where the galleries split in two different branches (see again Fig. 6); we were able to go further on, for less than a meter.

We were able to draw a new plan of the subterranean tunnels, with the accessible and the buried parts outlined in blue or red (Fig. 13). When we superimposed our plan to the previous ones (Fig. 14), we saw that the T shaped tunnel of Piranesi (Fig. 14b) was wrong. The $\mathrm{V}$ shaped tunnels drawn by Salza Prina Ricotti (Fig. 14c) proved to be correct in their accessible part. On the contrary, the layout of their buried parts that we were able to detect is completely different from what she assumed, especially in the left branch of the tunnel.

Comparing our plan with the one by Piranesi, we also discovered that the buried left branch of the tunnel ended under the circular hall of the so called Apollo's temple (Fig. 15), 


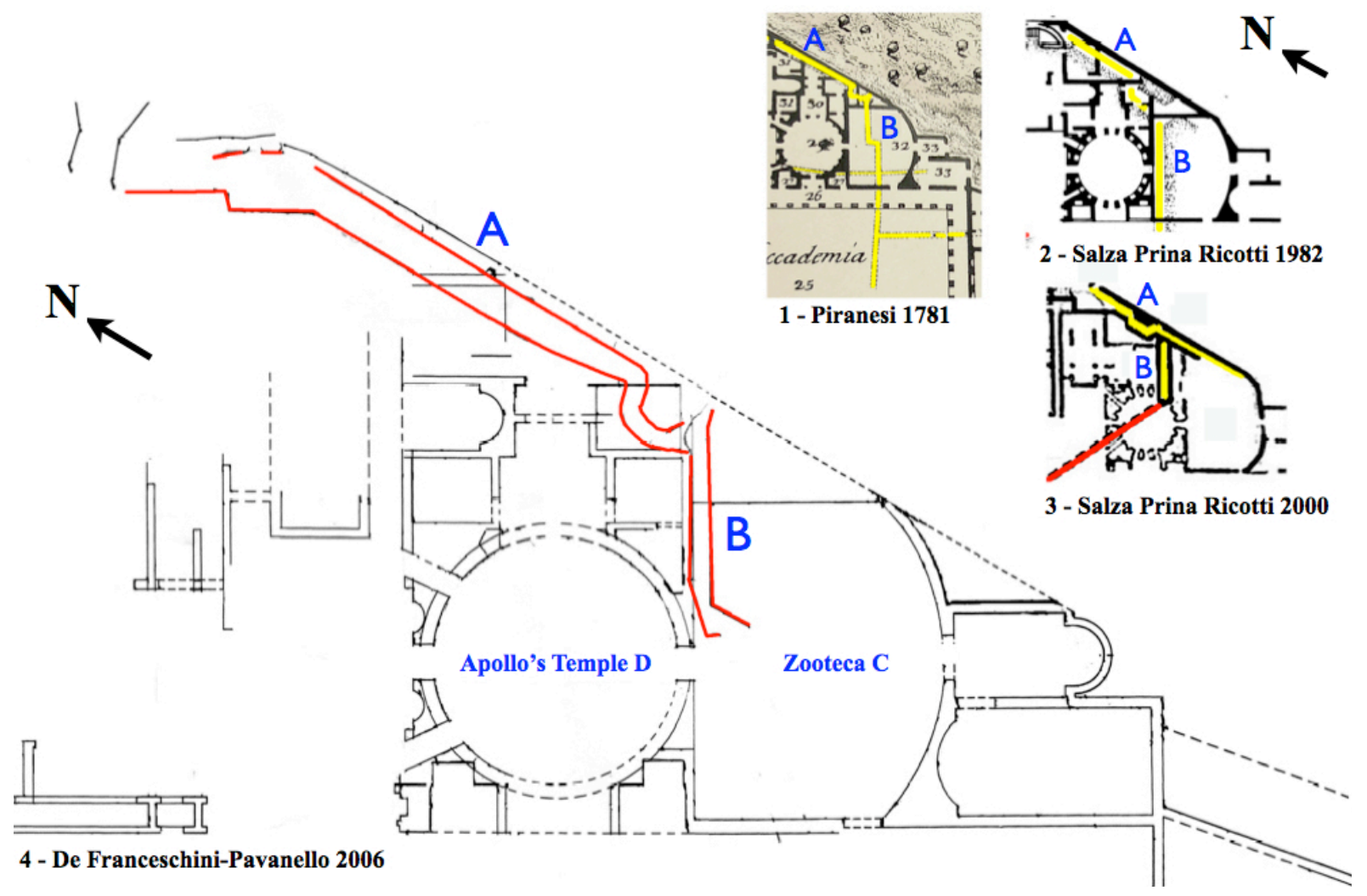

Fig. 3. Comparing ancient and modern plans of the subterranean network of service tunnels. 1: Piranesi 1781; 2: Salza Prina Ricotti 1982; 3: Salza Prina Ricotti 2000; 4: De Franceschini - Pavanello 2006. (A) Cryptoporticus; (B) corridors linked to the Cryptoporticus.

in the same point where Piranesi drew one of the galleries B (see Fig. 14b, marked by an asterisk). This is a very important result, because it proves that the two groups of tunnels (one linked to the Cryptoporticus A, the other to stair F) were connected together and belonged to one and same network of service galleries under the Accademia.

\section{Conclusions}

The plan of Piranesi is more than two centuries old but, despite the "technology" he used at his time, it proved to be surprisingly precise and reliable. It remains a fundamental starting point for any study or survey in Hadrian's Villa, an invaluable key to understand this extraordinary archaeological site.
Information technology makes it very easy to compare ancient and modern plans and to detect and correct their faults and mistakes. Geophysics is a non-invasive and nondestructive method of survey, which gave very interesting and significant results. We plan to use it more extensively in the Accademia to detect the layout of other subterranean tunnels visible in the antiquarian plans. 


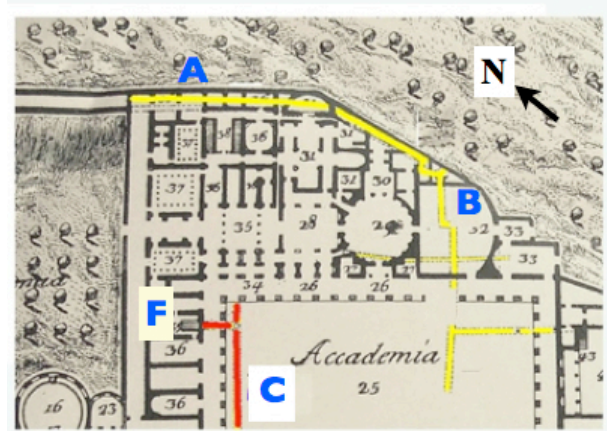

a - Piranesi, plan of 1781

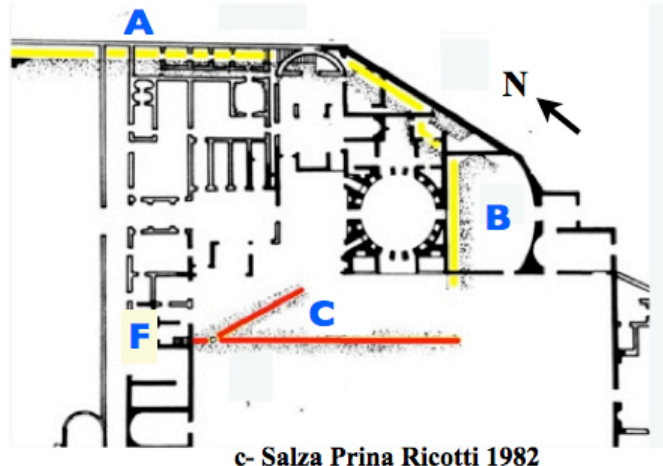

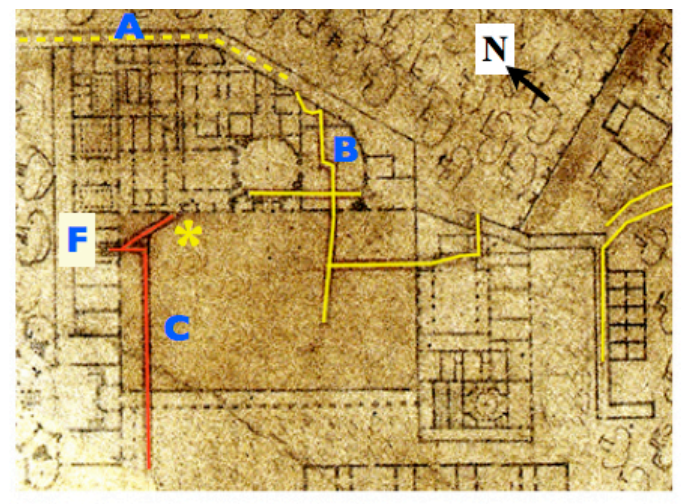

b - Piranesi, preparatory drawing in Naples

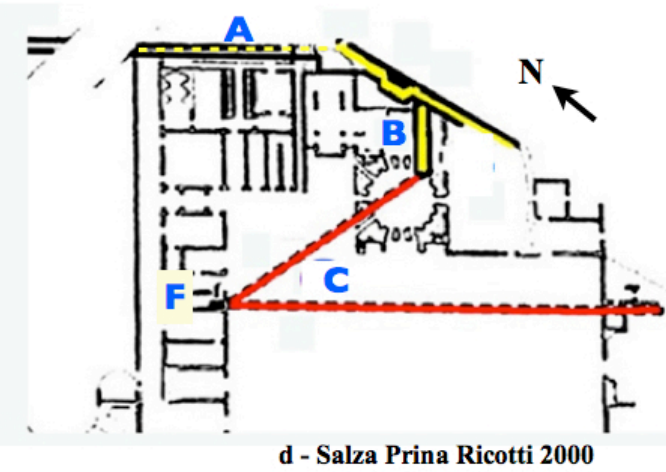

Fig. 4. Comparing ancient and modern plans of the tunnels $C$ under the main porch. (a) plan by Piranesi 1781; (b) preparatory drawing of Piranesi; (c) Salza Prina Ricotti 1982; (d) Salza Prina Ricotti (2000).

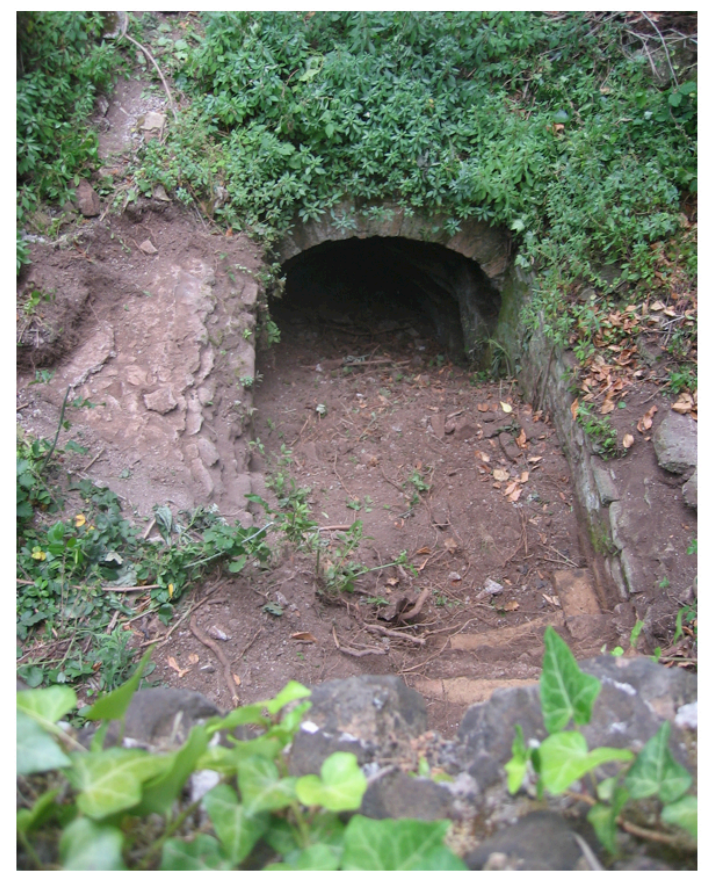

Fig. 5. The stair F descending to the subterranean tunnel C (photo M. De Franceschini). 


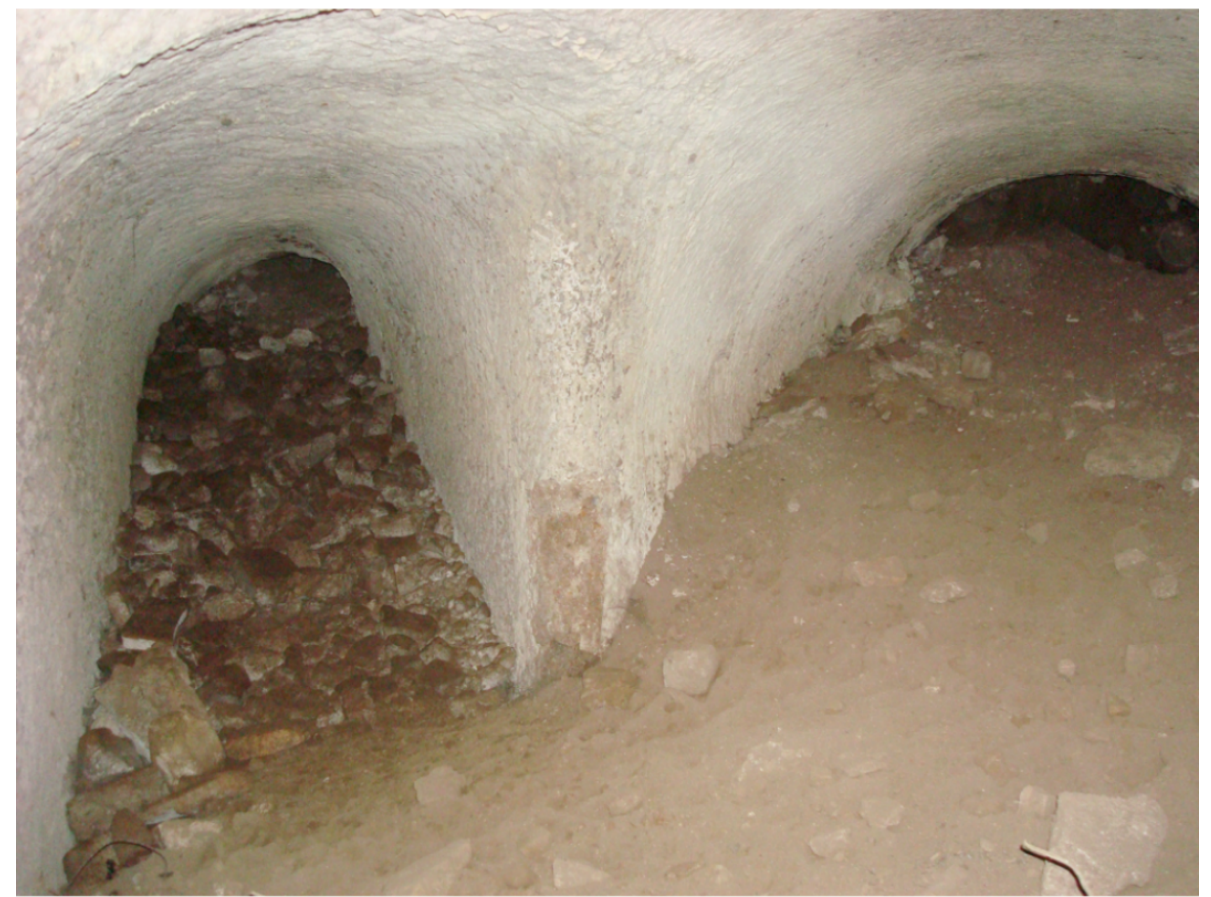

Fig. 6. The last accessible part of tunnel C, where it splits in two different galleries (photo M. De Franceschini).

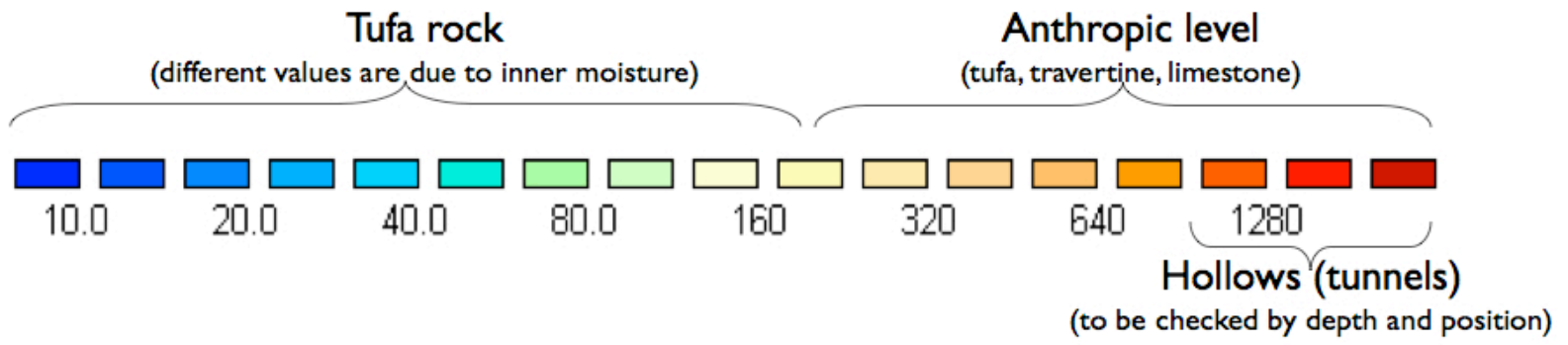

Fig. 7. Our resistivity scale of colors, corresponding to different materials (A. M. Marras). 


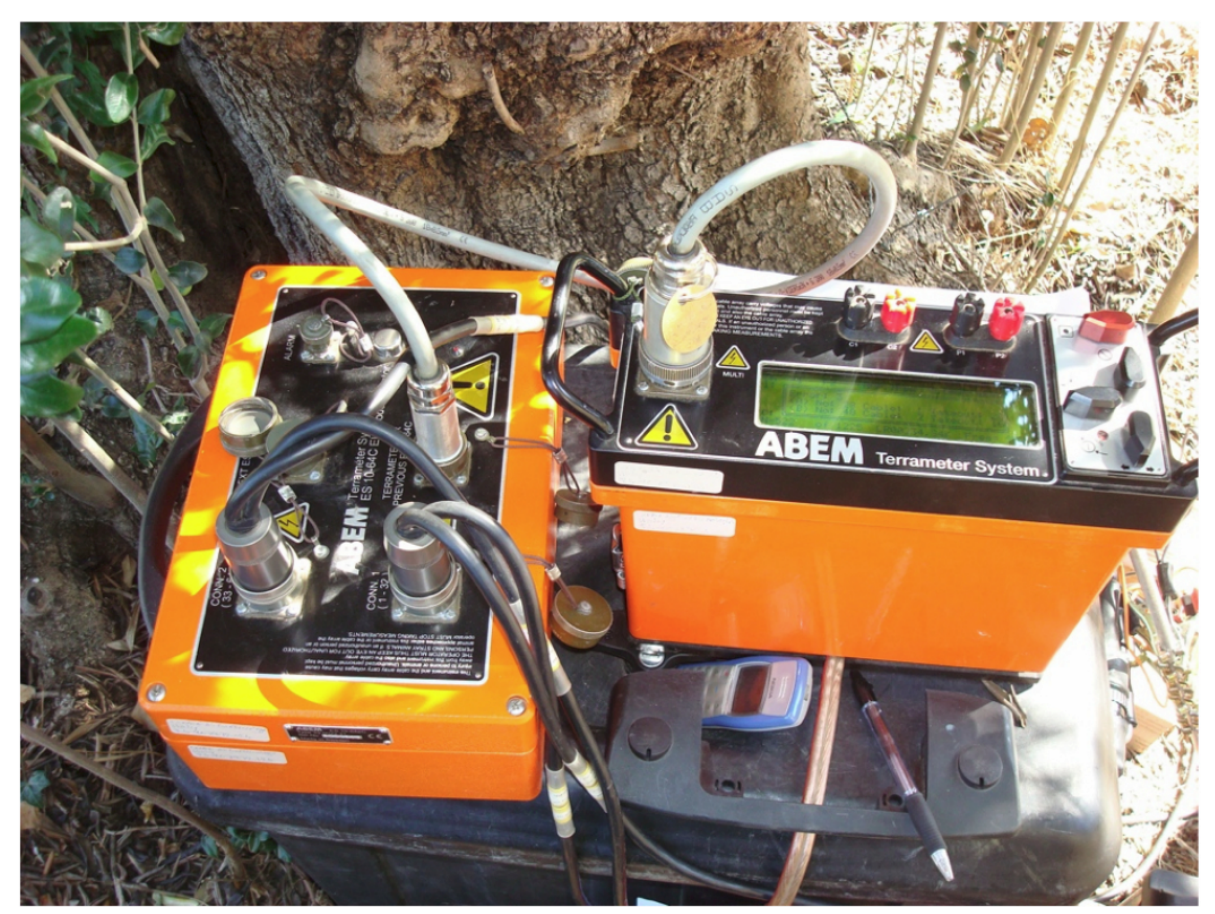

Fig. 8. The Geo-Resistivimeter used in our survey, a Terrameter SAS 1000, built by Abem Instrument (Sweden) (photo A. M. Marras).

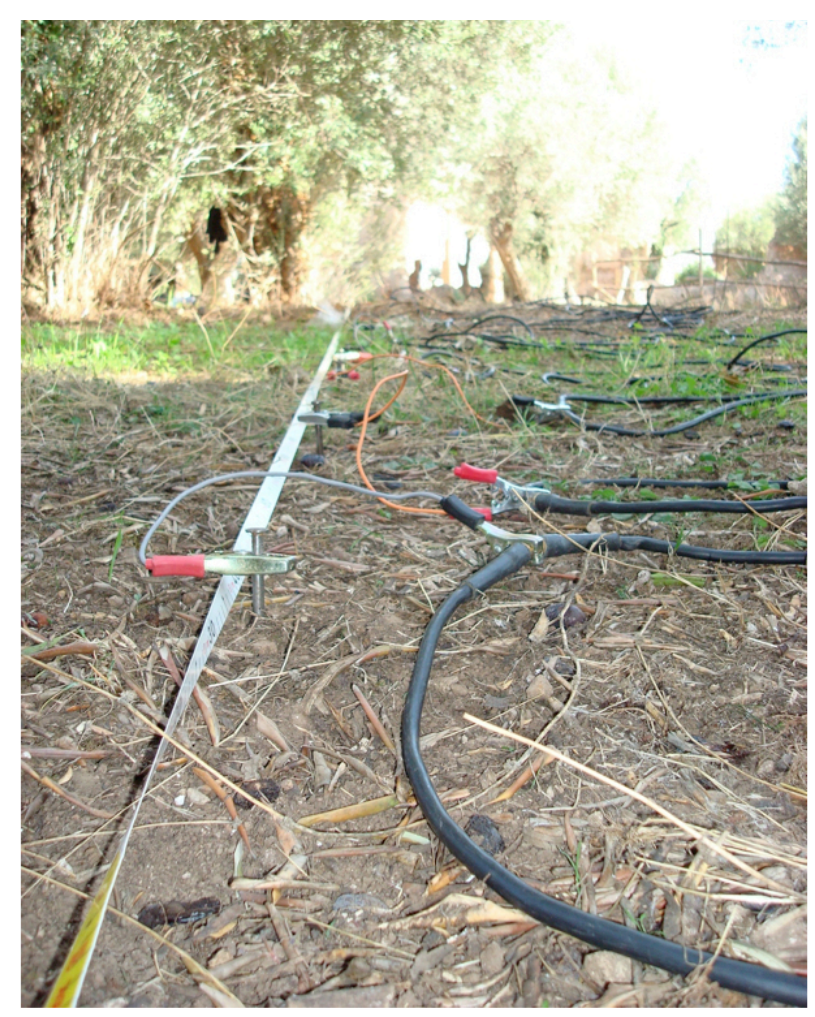

Fig. 9. Detail of the electrodes used in our survey (photo A. M. Marras). 


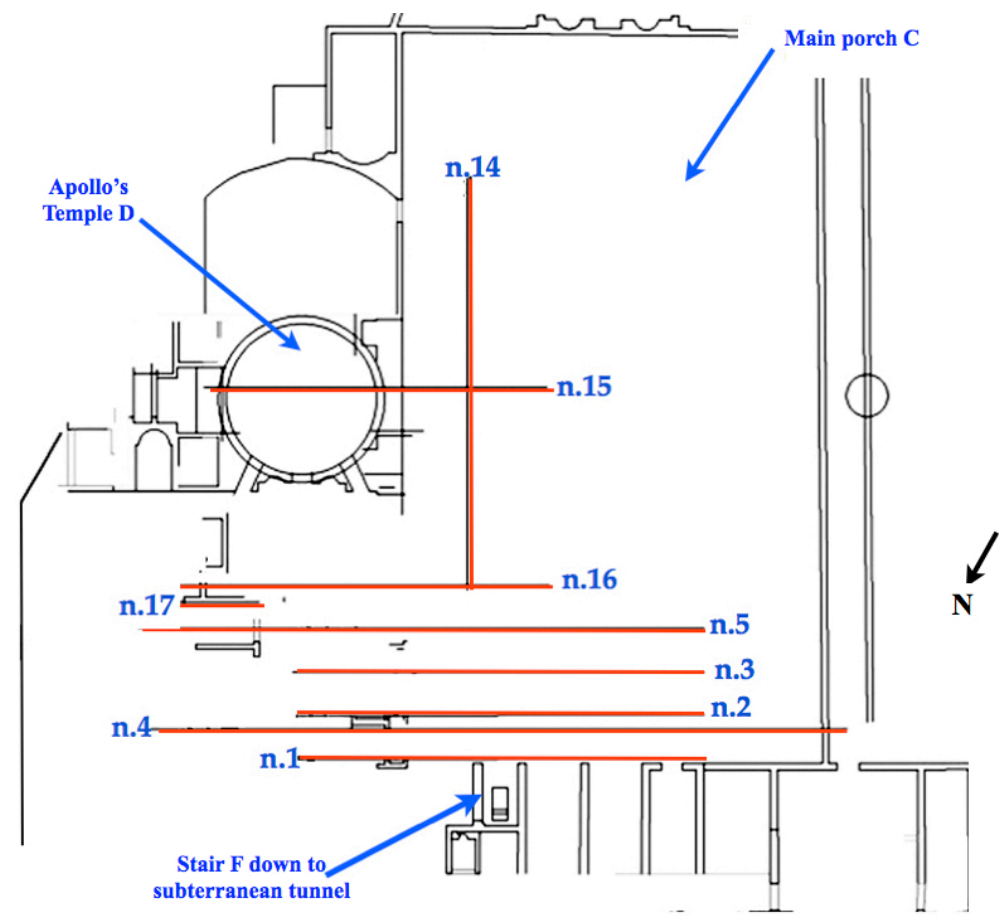

Fig. 10. Plan of our geo-resistivimeter measurements (A. M. Marras).

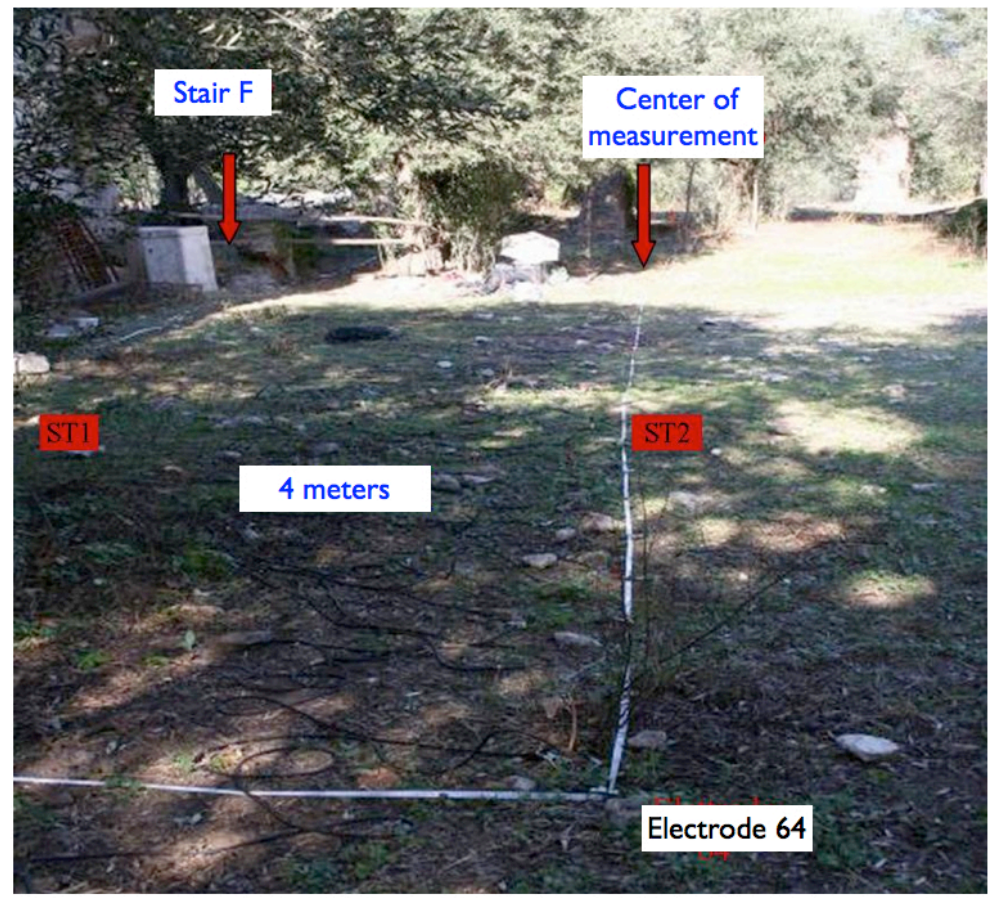

Fig. 11. View of the surveyed area in the northern part of the inner porch, with part of the measuring grid (photo A. M. Marras). 


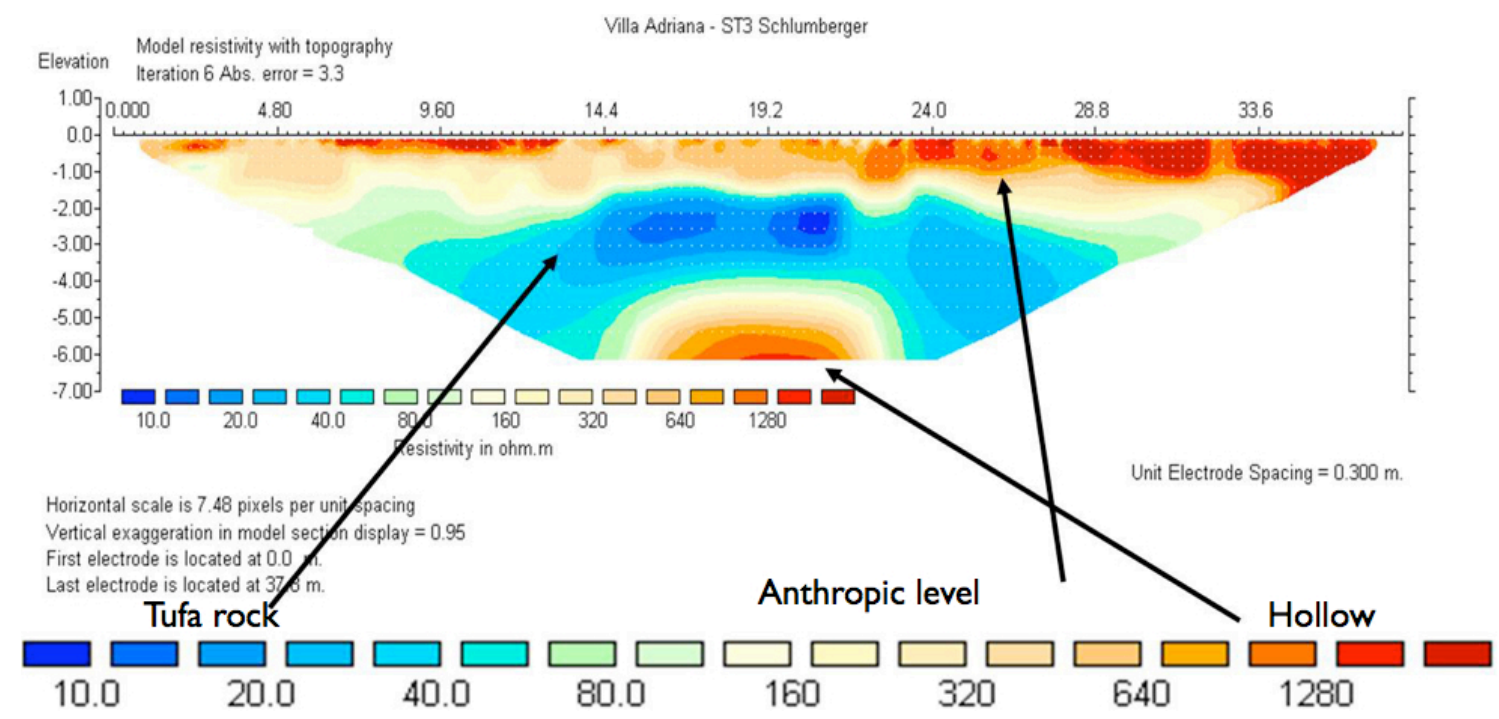

Fig. 12. Model resistivity of our survey (A. M. Marras).

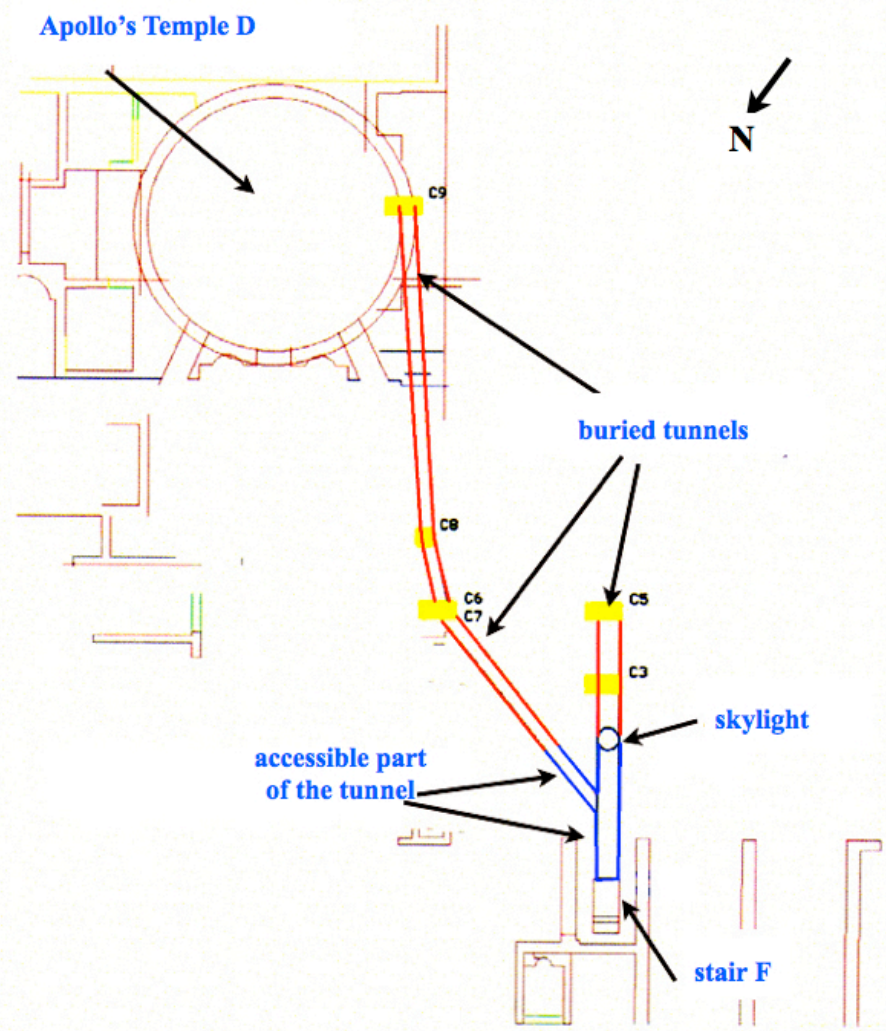

Fig. 13. Our new plan of the subterranean tunnels under the Accademia main porch. The accessible part of the tunnels is outlined in blue, the layout reconstructed with geo-resistivimeter is in red (photo A. M. Marras). 


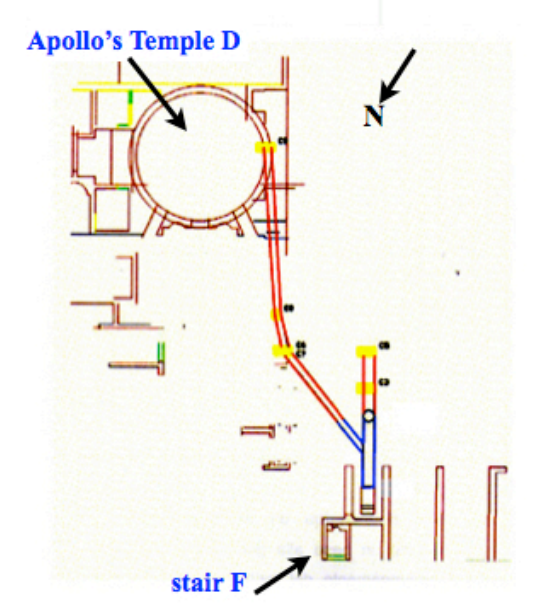

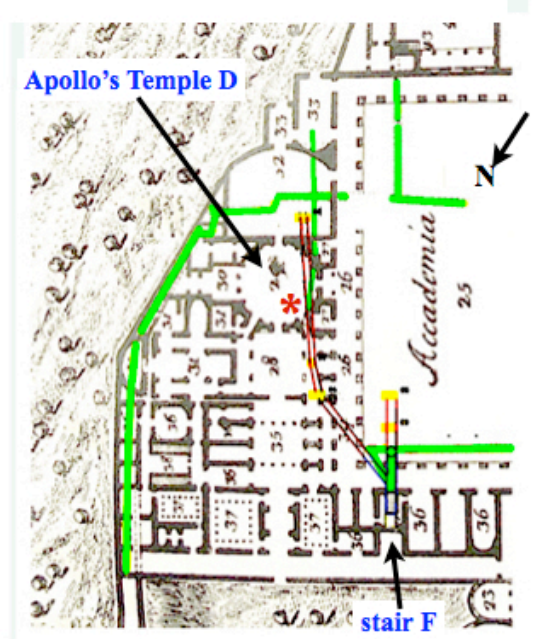

b - plan Piranesi 1781

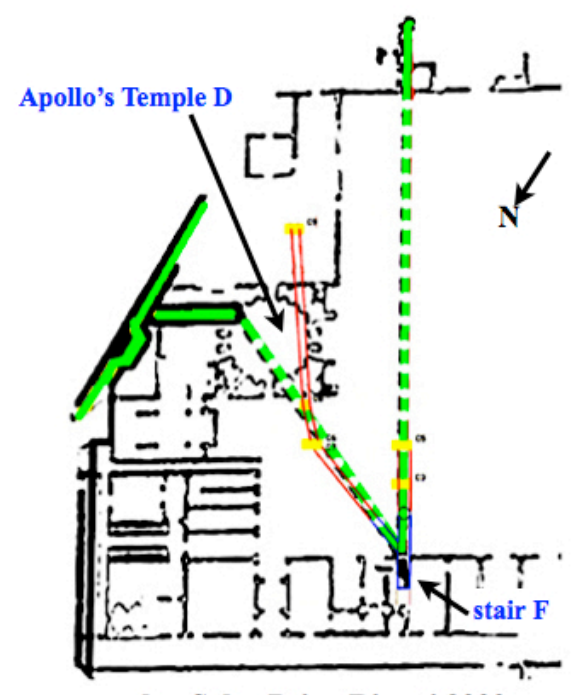

c - plan Salza Prina Ricotti 2000

a - Geo-electric survey Marras 2007 and

Fig. 14. Comparing our new plan (by A. M. Marras) with the previous ones. (a) layout of the tunnels superimposed to our new plan; (b) the same over the plan by Piranesi: the asterisk shows where our tunnel connects to the one drawn by Piranesi under the Apollo's Temple; (c) over the plan by Salza Prina Ricotti: her layout (in green) was proven wrong for the left branch of the tunnel.

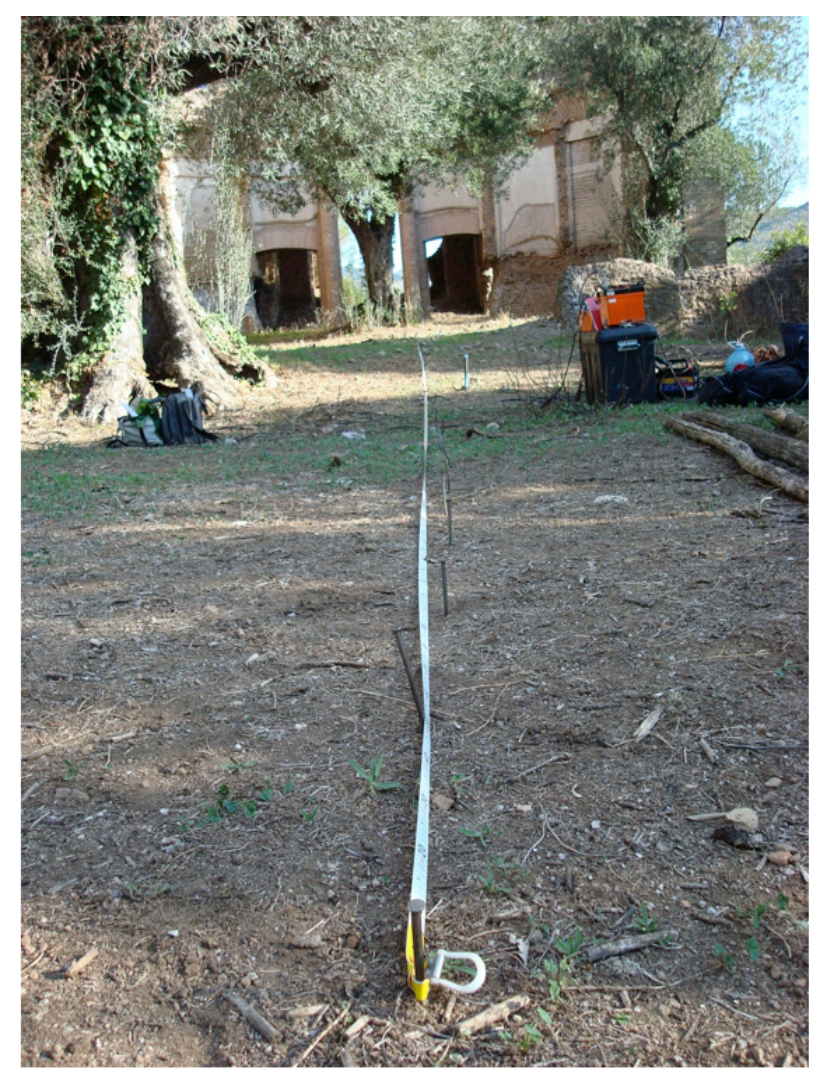

Fig. 15. Measurement n. 15 and the Apollo's Temple in the background (see plan Fig. 10) (photo A. M. Marras). 
Acknowledgements. I am grateful to Daniela Bulgarini who kindly gave me permission to explore and study the site of the Accademia.

I also thank: architect Umberto Pavanello who surveyed the Accademia with me to draw the new plan; Dott.ssa Anna Maria Marras who chose to study the Accademia for her Master thesis; Professor Fabio Mantovani and dott.ssa Marta Bottacchi of the University of Siena, Italy (Centro di Geo Tecnologie of San Giovanni Valdarno), who provided the instruments and technical support for the survey.

This technique, combined with future Remote Sensing surveys, will surely yield new discoveries.

I am particularly grateful to Architects Faller, Helfgen and Krück for giving me the documentation of their work with professor Rakob. And - last but not least - to Robert Mangurian and Mary-Ann Ray for sharing with me their knowledge of the Villa.

Edited by: L. Eppelbaum, N. Masini, and F. Soldovieri Reviewed by: two anonymous referees

\section{References}

A complete and selected bibliography on Hadrian's Villa can be found on my website www.villa-adriana.net

Contini, F.: Hadriani Caesaris immanem in agro tiburtino villam, Roma, Italy, tav. VIII, 1668.

De Franceschini, M.: Villa Adriana - Mosaici, pavimenti, edifici, Roma, Italy, 321-356, 582-591, 1991.
Hidalgo, R.: Piranesi y el dibujo preparatorio de la Pianta delle fabbriche esistenti nella Villa Adriana del Museo de San Martino en Nàpoles in El Concepto de lo provincial en el mundo antiguo. Homenaje a la profesora Pilar Leòn Alonso, Cordoba, 281-300, 2006.

Kähler, H.: Hadrian und seine Villa bei Tivoli, Berlin, Germany, 27, 73-84, 128-132, 1950.

Lui, F.: Des ruines aux bibliothèques. Piranesi e il mondo francese: fortuna, suggestioni, eredità in La Roma di Piranesi. La città del Settecento nelle Grandi Vedute, Roma, Italy, 79-90 (Fig. 2, p. 80), 2006.

Marras, A. M.: L'Accademia di Villa Adriana: rilettura delle piante antiche attraverso le indagini geoelettriche. Tesi per Master universitario di II livello in Geotecniche per l'Archeologia. Tutor Dott. Fabio Mantovani e Dott.ssa Marta Bottacchi, S. Giovanni Valdarno, 2008.

Pinto, J.: Piranesi at Hadrian's Villa in Eius virtuti studiosi. Classical and Postclassical Studies in Memory of Frank Edward Brown, 1900-1988, Washington, USA, 464-477, 1993.

Piranesi, G. B.: Pianta delle fabbriche esistenti nella Villa Adriana, Roma, tav. III, nos. 12-46, 1781.

Salza Prina Ricotti, E.: Villa Adriana nei suoi limiti e nella sua funzionalità in Rendiconti della Pontificia Accademia Romana di Archeologia, Serie III, Memorie XIV, 25-55, 1982.

Salza Prina Ricotti, E.: Villa Adriana, il sogno di un imperatore. Architettura, arte e giardini, Roma, 277-280, 2000.

Winnefeld, H.: Die Villa des Hadrian bei Tivoli in Jahrbuch des Deutsches Archäologisches Instituts Rom, Erganzungshefte 5, 111-119, 121, 1895. 